(2) OPEN ACCESS

${ }^{1}$ Centre for Health Equity Training, Research and Evaluation (CHETRE), University of New South Wales, Liverpool, NSW, Australia

${ }^{2}$ Population Health, South Western Sydney Local Health District, Liverpool, NSW, Australia

${ }^{3}$ Ingham Institute for Applied Medical Research, Ingham Institute for Applied Medical Research, Liverpool, NSW, Australia

\section{Correspondence to} Professor Evelyne de Leeuw, CHETRE, University of New South Wales, Liverpool, NSW 1871, Australia; e.deleeuw@unsw.edu.au

Received 8 July 2021 Accepted 13 October 2021

Published Online First 27 October 2021

Check for updates

(C) Author(s) (or their employer(s)) 2022. Re-use permitted under CC BY-NC. No commercial re-use. See rights and permissions. Published by BMJ.

To cite: de Leeuw E. J Epidemiol Community Health 2022:76:206-208.

\title{
Intersectorality and health: a glossary
}

Evelyne de Leeuw

$1,2,3$

Intersectorality has become an unchallenged article of faith in health thinking. ${ }^{1}$ The term 'intersectoral action' first formally entered the literature in the 1970 s. $^{2} 3$ It came about when a technical advisory group at WHO contemplated the challenges in sanitation. The technical advisors acknowledged that traditional infectious disease and public health personnel needed to connect with engineering and water management specialists, and that each of these came from a particular disciplinary and government background. Joint work through intersectoral action was deemed critical for the success of sanitation.

The term soon entered more policy focused and political realms. Following the Declaration of Alma Ata ${ }^{4}$ 'intersectoral action' was not merely a technical approach, but became a statement of principle. Primary health would only reach its full effectiveness potential, 'Alma Ata' declared, when many sectors were engaged in it. $^{25}$ Variations on the terminology started to proliferate. Working across sectors was variously deemed intersectoral action, policy, collaboration and cooperation. The term multisectoral also entered the health vernacular-the suggestion here is that a group of sectors pursues a similar goal, rather than necessarily working together to achieve a particular goal. However, recent discourse proposes that the term 'multisectoral action for health' includes all actor and sector configurations that include non-health sectors to-deliberately or as a collateral-potentially improve health. ${ }^{6}$

The proliferation of intersectoral terminology coincided with similar developments in policy development and administrative and political science scholarship. Partly sponsored by global think tanks such as the World Bank and the international aid industry there was a call for, variously, 'Whole of Government' (WoG), 'Joined-up Government' (JUG) and horizontal, integrated or coordinated ${ }^{7}$ policy making.

In recent years, these streams of consciousness seem to have coalesced in calls for Health in All Policies (HiAP). Several reviews ${ }^{8}$ and glossaries ${ }^{910}$ have endeavoured to transcend the evangelical approach to HiAP and its conjoint predecessor Healthy Public Policy. These reviews and glossaries purportedly show what is required to develop and maintain coherent society-wide actions, policies and governance for health.

However, the terminology associated with intersectorality is not always unequivocal. The fact that multiple meanings may exist in multiple contexts does not necessarily enable a focused, and practically or scholarly sound, developmental strategy to achieving such goals. This is becoming a more acute challenge with the increased, and prominent, recognition that health is both an endpoint of a multitude of reciprocating dynamics, as well as an input for individual, social and global change. This is evident in agendas set by the Sustainable Development Goals ${ }^{11}$ and, for instance, planetary health paradigms. ${ }^{12} 13$

An appropriate clarification and distinction of terms and their meaning around intersectorality is sensible-it would advance coherent scholarship and practice of this essential area of health and health equity development.

\section{WHAT IS A SECTOR?}

At the core of this glossary must be a strong delineation of what constitutes a sector. Degeling ${ }^{14}$ writes that sectors do not exist as naturally occurring phenomena- sectors are constructed, sometimes as rhetorical devices, sometimes for management purposes. In a process Degeling calls ‘sectoring', sectors align with disciplinary and paradigmatic ontologies, and they firm up as unassailable institutions (in the sociological sense as 'implicit arrangements', and not necessarily as the hardware associated with government or industry structures). 'Sectoring' is a function of Weberian bureaucracy, aiming at achieving hierarchical and distinct efficiencies. Laumann and Knoke ${ }^{15}$ determine such sectors as policy domains, which they can describe as (social and organisational) network maps. In their study of energy and health domains they show strong inner cores of those networks, with more fuzzy peripheral organisational and individual actors. Such a more graphic representation of 'sectors' moves beyond the hegemonic approach (using terms such as 'pillars' or 'silos') that has also led to conceptualisations such as the 'medical-industrial complex' in which inseparable capitalist interests exert impregnable power and control over all health efforts-a rather disempowering view of the world. Degeling asserts that sectors are largely the result of social construction, and that through a process of reticulisation (individual and institutional driven connectedness and joint commitment-in some circles described as the rhizome of health action ${ }^{16}$ ) the boundaries between sectors can start to dissolve. Apart from this conceptual reflection on the core-and-fuzziness of sectors, McQueen et $a l^{17}$ functionally define the health sector as 'all organisations, stakeholders and procedures in the remit of the minister responsible for health, which includes the ministry and other related statutory organisations.' This hierarchical public policy view may equally apply to other government arenas, thus turning, for instance, the 'agriculture sector' into 'all organisations, stakeholders and procedures in the remit of the minister responsible for agriculture, which includes the ministry and other related statutory organisations' and so forth. There are two drawbacks to such definitional assertions.

First, the operative construct may be fuzzily defined, and second, it takes a fairly conservative 
view of government, indeed a la Weber. 'The minister responsible for health' may well be responsible for health, but usually is restricted in her accountabilities and control to health service delivery (re)distributional intervention efforts. ${ }^{5}$ This, in fact, creates a 'health sector' that is nothing more than a 'disease repair sector'. If the minister genuinely were responsible for health, the remit of her portfolio and range of communicative, regulatory, and facilities efforts would be much wider and in fact enable the constructive engagement of domains that exert influence over the dimensions of social, commercial and political determinants of health. Second, views of modern government have first embraced, and then transcended neoliberal 'new public management ${ }^{18}$; the resulting devolution of the primacy of government roles has made the calls for policy integration more acute. The contemporary challenge is dealing with the dynamically networked reality of governing. ${ }^{19}$ To assign sectorshaping clout to a ministry (and its top functionary) alone is, in these contexts, ambitious at best and unrealistic at worst.

A contemporary sector, therefore, can best be defined as 'an intricate web of interdependent organisations, individuals and behaviours, implicitly or explicitly driven by beliefs or assumptions to pursue a set of interconnected ideals, goals and objectives through the variously dispersed and joint control and allocation of resources.' This web could be as tight or loose as the participants in the sector allow it to be.

\section{INTERSECTORAL ACTION}

The first instance where intersectoral action achieved codification was in Harris et $a^{20}:$ A recognised relationship between part or parts of the health sector and part or parts of another sector, that has been formed to take action on an issue or to achieve health outcomes, (or intermediate health outcomes) in a way which is more effective, efficient or sustainable than could be achieved by the health sector working alone. A WHO conference 3 years later confirmed this definition ${ }^{21}$ and this is generally referenced as the authoritative version.

Intersectoral, intersectorial, multisectoral and even multisectorial all seem fanciful variations on the same theme. In one of its resolutions, the World Health Assembly ascertained that ' $(\mathrm{T})$ he term 'multisectoral action' refers to action between two or more sectors within the public sector and is generally interchangeable with "intersectoral action". ${ }^{22}$ In an influential series of reflections, Rasanathan et $a l^{6}$ provide an epistemic typology. They write that multisectoral action for health 'encompasses all activities involving non-health sectors that can potentially improve health'. The typology outlines patterns of health-led or 'nonhealth'-led effects, policies and collaborations. As noted above, Rasanathan et al frame 'intersectoral' as a subset of 'multisectoral'. Both are driven by interests, institutions and ideas, the authors purport. For policy and practice for health their analysis does not offer great instrumentality. In fact, if the quality of the prefix does not really matter, one could come up with even more whimsical variants such as nullisectoral, parasectoral, plurisectoral, aposectoral or supersectoral-each indicating that the distinction of, and between, sectors does not quintessentially matter. But the mere existence and nature of sectors, and the fact that each of them separately (and in combination, synergistically) determines health and health equity is sufficient reason to be precise about our language. Multisectoral, therefore, denotes approaches that involve more than one sector, but not necessarily in a deliberate or coordinated manner, and intersectoral indicates organised efforts to align approaches between sectors. Unless there are compelling semantic or semiotic reasons, further word fantasies on this theme are to be discouraged. This is concordant with the extant distinctions between multidisciplinary and interdisciplinary approaches. ${ }^{23}$

\section{INTERSECTORAL COLLABORATION}

In subsequent intersectoral applications and considerations, however, the health field used the 'action' extension with increasing flexibility, either to reflect on the existing need, or to cast the conceptual and heuristic net wider. 'Action', to many, now seems to include 'collaboration', 'policy' and 'governance'.

The majority of the health science literature, in defining 'intersectoral collaboration', regurgitates the above definition of 'intersectoral action'. Conceptually and systematically, however, collaboration and action are qualitatively different things. Based on theorising by Wood and Gray the proposition is to define intersectoral collaboration as 'occurring when a group of autonomous stakeholders of a problem domain engage in an interactive process, using shared rules, norms and structures, to act or decide on issues related to that domain'. ${ }^{24}$ Intersectoral collaboration therefore is not an outcome, it is the process, and one that requires vigilant and constant dynamic engagement. Different forms of collaboration emerge from the literature. For instance, depending on disciplinary foundations there may be a specification along scales of tightness and integration of organisational degrees of freedom. On one end of the scale, collaboration can be framed as communication, on the other hostile take-over and merger. ${ }^{25}$ Distinctions in collaboration may also play out across jurisdictions, horizontally (between like-level agents) and vertically (across hierarchies). This has been detailed for, for instance, the exegesis of the gospel of Primary Health Care, ${ }^{26}$ or for policy learning. ${ }^{27}$

\section{INTERSECTORAL POLICY AND GOVERNANCE}

Whereas collaboration is a fluid mechanism, ${ }^{28}$ (intersectoral) policy and governance appear to be entities/issues with a degree of stability. Intersectoral health policy is equivalent to HiAP, defined as 'an approach to public policies across sectors that systematically takes into account the health implications of decisions, seeks synergies and avoids harmful health impacts in order to improve population health and health equity. It improves accountability of policy-makers for health impacts at all levels of policy-making. It includes an emphasis on the consequences of public policies on health systems, determinants of health and well-being. ${ }^{29}$

A range of intersectoral actions, collaborations and policies may well lead to intersectoral governance. This can be defined as 'the sum of the many ways individuals and institutions, public and private, manage the connections of their common affairs. It is a continuing process through which conflicting or diverse interests may be accommodated and cooperative action may be taken. It includes formal institutions and regimes empowered to enforce compliance, as well as informal arrangements that people and institutions either have agreed to or perceive to be in their interest. ${ }^{.30} 31$

\section{INTEGRATION: JUG AND WOG}

Deliberate intersectorality (whether action, collaboration, policy or governance) requires vision, engagement and intervention for coordination and integration. These are not new challenges, neither to the health field nor to general governance systems. Guy Peters, one of the gurus of administrative science has identified (intersectoral) policy integration as the holy grail of any government in the world. ${ }^{32}$ Trein et $a l^{33}$ undertook a rigorous review of the world 
of coordinated public policies and found that policy integration approaches predominantly focus on the alignment and coherence of the substance of particular policies. A policy can be conceptualised in many ways, but in this context includes the identification of a social problem, a public sector response and accountability mechanism (eg, a decision by an elected body), their decisions on the allocation on resources and their (re)distributive mechanisms and conditions for realising aspirations. ${ }^{34}$

Another gaze at integration and coordination of sectors, and the second mechanism in the Trein et al review, ${ }^{33}$ uses the moniker JUG and WoG or WG. These approaches hinge on governments in nation-state and other jurisdictions, and in the assumed governmentality of social issues. They more deliberately integrate not just horizontally (ie, between sectors or 'silos') but also between levels of government (on a scale typically between national and neighbourhood government presence-but for some, particularly in contemporary analyses of global health, including transnational and international levels ${ }^{35}$ ). The 'WoG' approach is one in which public service agencies work across portfolio boundaries, formally and informally, to achieve a shared goal and an integrated government response to particular issues. It aims to achieve policy coherence in order to improve effectiveness and efficiency. This approach is a response to departmentalism that focuses not only on policies but also on programme and project management. ${ }^{1936}$

Twitter Evelyne de Leeuw @evelynedeleeuw

Contributors EdL has solely and exclusively conceptualised, researched and authored this work.

Funding The authors have not declared a specific grant for this research from any funding agency in the public, commercial or not-for-profit sectors.

Competing interests None declared.

Patient consent for publication Not applicable.

Provenance and peer review Not commissioned; externally peer reviewed.

Open access This is an open access article distributed in accordance with the Creative Commons Attribution Non Commercial (CC BY-NC 4.0) license, which permits others to distribute, remix, adapt, build upon this work non-commercially, and license their derivative works on different terms, provided the original work is properly cited, appropriate credit is given, any changes made indicated, and the use is non-commercial. See: http://creativecommons.org/licenses/by-nc/4.0/.

\section{ORCID iD}

Evelyne de Leeuw http://orcid.org/0000-0003-3434-1439

\section{REFERENCES}

1 De Leeuw E. Intersectoral Action. In: De Leeuw E, ed. Oxford bibliographies in public health. New York: Oxford University Press, 2021.

2 World Health Organization. National environmental health programmes : their planning, organization, and administration, re-port of a WHO Expert Committee on the Planning Organization, and Administration of National Environmental Health Programmes \& World Health Organization [imeeting held in Geneva from 3 to 11 June 1969]: World Health Organization technical report series; no. 439 Geneva: World Health Organization, 1970. Available: https://apps.who.int/iris/handle/10665/40768

3 Mahler H. Present status of WHO's initiative, "Health for all by the year 2000". Annu Rev Public Health 1988;9:71-97.

4 World Health Organization \& United Nations Children's Fund (UNICEF). International Conference on Primary Health Care (1978: Alma-Ata, USSR), (1978). Primary health care : report of the International Conference on Primary Health Care, Alma-Ata, USSR, 6-12 September 1978 / jointly sponsored by the World Health Organization and the United Nations Children's Fund. Geneva: World Health Organization, 1978. https:// apps.who.int/iris/handle/10665/39228

5 World Health Organization. Intersectoral action for health: the role of Intersectoral cooperation in national strategies for health for all. Geneva: WHO, 1986. http://apps. who.int/iris/bitstream/10665/41545/1/9241560967_eng.pdf

6 Rasanathan K, Bennett S, Atkins V, et al. Governing multisectoral action for health in low- and middle-income countries. PLoS Med 2017;14:e1002285.

7 Rayner J, Howlett M. Introduction: understanding integrated policy strategies and their evolution. Policy and Society 2009;28:99-109. 2009.
8 de Leeuw E. Engagement of sectors other than health in integrated health governance, policy, and action. Annu Rev Public Health 2017;38:329-49.

9 Freiler A, Muntaner C, Shankardass K, et al. Glossary for the implementation of health in all policies (HiAP). J Epidemiol Community Health 2013;67:1068-72.

10 Oneka G, Vahid Shahidi F, Muntaner C, et al. A glossary of terms for understanding political aspects in the implementation of health in all policies (HiAP). J Epidemiol Community Health 2017;71:835-8.

11 Ramirez-Rubio O, Daher C, Fanjul G. Urban health: an example of a "health in all policies" approach in the context of SDGs implementation. Global Health 2019;15:1-21.

12 Clark H. Governance for planetary health and sustainable development. Lancet 2015;386:e39-41.

13 De Leeuw E. Interplanetary health equity: implications of dominant value systems in space exploration for human cultural identity and equitable survival. 9th Annual Conference. InVIVO Planetary Health. Project Earthrise. People. Place. Purpose. Planet, 2020. Available: https://custom.cvent.com/FE8ADE3646EB4896BCEA8239 F12DC577/files/428fe0df03c04eb8884e47766014dc33.pdf and https://vimeo.com/ 481083177

14 Degeling P. The significance of 'sectors' in calls for urban public health intersectoralism: an Australian perspective. Policy \& Politics 1995;23:289-301.

15 Laumann EO, Knoke D. The organizational state: social choice in national policy domains. Madison: Univ of Wisconsin Press, 1987.

16 Dupéré S, Ridde V, Carroll S. Conclusion: the rhizome and the tree. In: Health promotion in Canada: critical perspectives. Toronto: Canadian Scholars, 2007: 371-88.

17 McQueen DV, Wismar M, Lin V. Intersectoral governance for health in all policies: structures, actions and experiences. Copenhagen: World Health Organization. Regional Office for Europe, 2012.

18 Gruening G. Origin and theoretical basis of new public management. International Public Management Journal 2001;4:1-25.

19 Provan KG, Kenis P. Modes of network governance: structure, management, and effectiveness. Journal of Public Administration Research and Theory 2008;18:229-52.

20 Harris E, Wise M, Hawe P. Working together: intersectoral action for health. Canberra: Australian Government Publishing Service, 1995.

21 Kreisel W, von Schirnding Y. Intersectoral action for health: a cornerstone for health for all in the 21st century. World Health Stat Q 1998;51:75-8.

22 World Health Assembly. Contributing to social and economic development: sustainable action across sectors to improve health and health equity (follow-up of the 8th global conference on health promotion). Report of the Secretariat. SIXTYEIGHTH World health assembly A68/17 provisional agenda item 14.5 18, 2015. Available: https://apps.who.int/gb/ebwha/pdf_files/WHA68/A68_17-en.pdf [Accessed July 2021].

23 Lawrence RJ. Deciphering interdisciplinary and Transdisciplinary contributions. Transdiscip/ J Eng Sci 2010;1.

24 Wood DJ, Gray B. Toward a comprehensive theory of collaboration. J App/ Behav Sci 1991;27:139-62.

25 Todeva E, Knoke D. Strategic alliances and models of collaboration. Management Decision 2005:43:123-48.

26 De Maeseneer J, van Weel C, Egilman D. Strengthening primary care: addressing the disparity between vertical and horizontal investment. in quality of primary health care: the perspective of patients. Br J of Gen Prac 2008;58:3-4.

27 Hawkins B, Holden C, Mackinder S. The Battle for Standardised Cigarette Packaging in Europe. Multi-Level Governance, Policy Transfer and the Integrated Strategy of the Global Tobacco Industry. In: Fafard P, de Leeuw E, eds. Multi-Level governance, policy transfer and the integrated strategy of the global tobacco industry. New York/London/ Melbourne: Palgrave Series in Public Health Policy Research, Palgrave, 2020.

28 Costumato L. Collaboration among public organizations: a systematic literature review on determinants of interinstitutional performance. Int J Public Sec Manag 2021;34:247-73.

29 Tang KC, Ståhl T, Bettcher D, et al. The eighth global conference on health promotion: health in all policies: from rhetoric to action. Health Promot Int 2014;29:11-8.

30 Commission on Global Governance. Our global neighbourhood: the report. Oxford: Oxford University Press, 1995.

31 de Leeuw E. Intersectoral action, policy and governance in European healthy cities. Public Health Panor 2015;1:175-82.

32 Peters BG. Managing horizontal government. The politics of coordination. research paper 21 Canadian centre for management development. Minister of supply and services, Ottawa, Canada, Catalogue number SC94-61/21-1998, 1998. Available: http://www. academia.edu/download/33172131/Guy_Peters_-_Policy_coordination.pdf

33 Trein P, Meyer I, Maggetti M. The integration and coordination of public policies: a systematic comparative review. J Comp Policy Anal Res Pract 2019;21:332-49.

34 de Leeuw E, Clavier C, Breton E. Health policy - why research it and how: health political science. Health Res Policy Syst 2014;12:1-11 http://www.health-policysystems.com/content/12/1/55

35 Nikogosian $\mathrm{H}$. The interface of multisectoral and multilateral dimensions of public health policy: what's new in the 21st century? J Public Health 2021:fdaa274.

36 Christensen T, Lægreid P. The whole-of-government approach to public sector reform. Public Adm Rev 2007;67:1059-66. 